\title{
Turismo em Macaé: possibilidades para um desenvolvimento mais sustentável da atividade
}

\author{
Erick da Cunha Coelho Zickwolff 1 \\ Universidade Federal Fluminense - UFF \\ Aline César Jesus ${ }^{2}$ \\ Prefeitura Municipal de Macaé \\ Leonardo Anderson da Silva ${ }^{3}$ \\ Presidente Macaé Convention \& Visitors Bureau \\ Vania Sodré Hatab ${ }^{4}$ \\ Prefeitura Municipal de Macaé \\ Glauber Henrique Santos Caldas ${ }^{5}$ \\ Prefeitura Municipal de Macaé
}

\section{RESUMO}

O presente trabalho tem como objetivo analisar as perspectivas da atividade turística no município de Macaé, levando em conta o conceito de sustentabilidade e sua efetiva aplicabilidade, tendo em mente a existência de um hiato entre a objetividade ideal do plano teórico, que o define de maneira absoluta, e a subjetividade específica da realidade, que dificulta sua plena realização. Para tanto, os autores realizaram uma pesquisa de cunho qualitativo, através de revisão bibliográfica de livros e artigos acadêmicos, bem como de notícias colhidas em sítios da internet. Fica patente, em primeiro lugar, a necessidade de se utilizar a terminologia "desenvolvimento sustentável" com cuidado e parcimônia, pois o patamar da sustentabilidade absoluta é um degrau inatingível nas atividades humanas, principalmente ao se pensar o sistema econômico vigente, qual seja, o capitalismo neoliberal. Macaé apresenta, sem dúvidas, possibilidades auspiciosas quanto à promoção de uma atividade turística que possa beneficiar o município em suas dimensões econômica, social, cultural, ambiental e política. Entretanto, para que tal intento se realize, de fato, seriam necessárias ações integradas entre as diversas esferas do poder público municipal, a iniciativa privada e o terceiro setor. Conclui-se que, sem a compreensão de que o turismo é um fenômeno complexo e que se conecta de forma intrínseca com as demais atividades realizadas em terras macaenses, seu desenvolvimento com vistas à sustentabilidade torna-se retórico e impraticável.

Palavras-chave: Turismo. Macaé. Desenvolvimento Sustentável.

\begin{abstract}
The current article aims to analyze the perspectives of tourism activity in Macaé, taking into account the concept of sustainability and its effective applicability, considering the existence of a gap between the ideal objectivity of the theoretical plan, which defines it in an absolute way, and the specific subjectivity of reality, which hinders its full realization. For this purpose, the authors carried out a qualitative research, performing a bibliographic review of books and articles, as well as collecting news on internet sites. Firstly, it's evident the need to use the terminology "sustainable development" with care and parsimony, since the level of absolute sustainability is an unattainable step in human activities, especially when it's considered the current economic system, that is, the neoliberal capitalism. Macaé undoubtedly presents auspicious possibilities regarding the promotion of a tourism activity that can benefit the municipality in its economic, social, cultural, environmental and political dimensions. However, for such an attempt to take place, in fact, it would be necessary to integrate actions between the various spheres: government, private sector
\end{abstract}

${ }^{1}$ Mestre em Turismo pelo Programa de Pós-Graduação em Turismo da Universidade Federal Fluminense.Turismólogo da Secretaria Municipal Adjunta de Turismo da Prefeitura de Macaé

${ }^{2}$ Prefeitura Municipal de Macaé

${ }^{3}$ Presidente Macaé Convention \& Visitors Bureau

${ }^{4}$ Prefeitura Municipal de Macaé

${ }^{5}$ Prefeitura Municipal de Macaé 
and the third sector. We conclude that, without understanding that tourism is a complex phenomenon and that it is intrinsically connected with the other activities carried out in Macaé, its development aiming sustainability becomes rhetorical and impracticable.

Keywords: Tourism. Macaé. Sustainable Development.

\section{Introdução}

A água é um recurso essencial à vida e vem adquirindo, nas últimas décadas, importância socioeconômica, política e cultural cada vez maior devido à sua irregular distribuição espacial no planeta. A sua escassez, em algumas partes do globo, já é considerada uma ameaça global, conforme destacado na $10^{a}$ edição do Fórum Econômico Mundial ocorrido em Genebra, em 2015 (Brauman, Richter, Postel, Malsy, M \& Florke, 2016).

As três últimas décadas do século XX testemunharam a intensificação da preocupação com o futuro da humanidade e do meio ambiente que o cerca e suporta, ainda que suas raízes estejam fincadas no século anterior. As promessas da Modernidade, de paz entre os homens e de desenvolvimento constante (baseadas nos ecos do lema da Revolução Francesa ${ }^{6}$ e nas ideias iluministas, e também nos avanços científicos e tecnológicos advindos da Revolução Industrial) não se concretizaram, sendo solapadas pelas Grandes Guerras Mundiais, pelo uso da energia nuclear como arma de destruição em massa e pela miséria imposta a milhões de seres humanos com a exploração de países coloniais por suas metrópoles europeias, além do predomínio do sistema de produção capitalista, fundamentado na distribuição desigual das riquezas por ele geradas.

No ano de 1987, a Comissão Mundial Sobre Meio Ambiente e Desenvolvimento, ligada à Assembleia Geral das Nações Unidas, lançou um documento de políticas globais chamado "Our Common Future"7, no qual propôs o conceito de "desenvolvimento sustentável". Desde então, diversos governos internacionais, organizações sem fins lucrativos, empresas e indivíduos passaram a adotar esta concepção como norteadora de suas atividades, buscando edificar um mundo mais justo e responsável, capaz de atender às necessidades de cada ser humano e conservar a natureza ao redor.

Apesar de expressar uma grande preocupação com a manutenção de toda a vida no planeta Terra, o conceito de desenvolvimento sustentável apresenta claras deficiências que, se ignoradas, terminam por transformá-lo em um discurso vazio, oco de sentido e respaldado em um horizonte utópico e inalcançável. Isto acontece porque é praticamente impossível conciliar as ideias contidas na sua formulação e o modo como a humanidade, de fato, se estrutura e produz seus meios de subsistência, bem como se relaciona com o meio do qual depende para sobreviver.

Assim, a discussão proposta neste artigo parte do pressuposto de que consideráveis mudanças precisam ser realizadas para que, de fato, se possa sequer pensar em falar em uma forma de desenvolvimento sustentável. Portanto, o melhor que talvez se possa e se deva fazer, levando em consideração as atuais condições em que a humanidade se apoia, é buscar diferenciar as ações "mais sustentáveis" daquelas "menos sustentáveis" e adotá-las com vistas a um progressivo aperfeiçoamento do desenvolvimento global.

O escopo do presente trabalho é, destarte, analisar a atividade turística no município de Macaé, localizado na Região Norte do Estado do Rio de Janeiro, procurando deslindar suas atuais manifestações, compreendendo a maneira como se desenvolveu até então e propondo ações que possam, futuramente, torná-la mais sustentável, buscando beneficiar - social e economicamente - o maior número de pessoas (moradores e turistas), ampliando a conservação da natureza, valorizando a cultura tradicional local e consolidando uma estrutura política capaz de, permanentemente, retroalimentar-se. 


\section{Metodologia}

Para a confecção do presente artigo, de caráter fundamentalmente qualitativo, os autores se utilizaram de pesquisa bibliográfica, através do exame de livros, artigos acadêmicos e sítios da internet, culminando com uma análise crítica da realidade da atividade turística em Macaé. Tal investigação foi baseada nos saberes teóricos apreendidos e culminou com a proposição de sugestões que possam servir de inspiração para a formulação de políticas governamentais - conforme especificado na chamada pública exposta no site da Prefeitura Municipal de Macaé - e para ações de cunho mais sustentável a serem executadas por representantes da iniciativa privada ou por membros do terceiro setor. $\mathrm{O}$ objetivo de sua realização é buscar compreender como a atividade turística pode ser desenvolvida de maneira racional e equilibrada no município. Para tanto, efetuou-se o cruzamento das informações teóricas coletadas na investigação, com a hodierna realidade macaense.

As duas primeiras seções do trabalho discutem o conceito de desenvolvimento sustentável, de maneira ampla, e a sua apropriação pelos estudiosos do fenômeno turístico, o que permite esquadrinhar a ideia do chamado "turismo sustentável". Em seguida, subvertendo

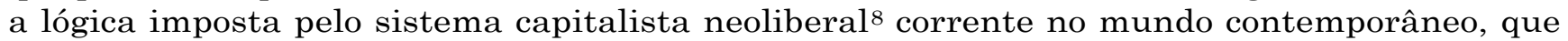
pressupõe os aspectos econômicos como os valores primordiais de medida e balizamento do desenvolvimento humano, os autores do presente artigo optaram por principiar sua investigação sobre as possibilidades de uma atividade turística sustentável em Macaé pelos seus aspectos ambientais, seguindo pelas preocupações sociais, passando por suas manifestações culturais e políticas e deixando o aspecto econômico para o final. Tal itinerário investigativo é uma forma simbólica de demonstrar que, apesar de toda a sua importância, sem a contemplação das demais esferas analíticas, o dinheiro, por si só, não possui o lastro necessário para explicar a complexidade das relações humanas, nem justificar a adoção de ações que podem prejudicar, indelevelmente, o meio em que se vive.

\section{O Que é Desenvolvimento Sustentável?}

O conceito de desenvolvimento sustentável mais difundido e até hoje em voga foi elaborado em 1987 pela Comissão Mundial Sobre Meio Ambiente e Desenvolvimento (1991, p. 46), que o define como sendo "aquele que atende às necessidades do presente sem comprometer a possibilidade de as gerações futuras atenderem às suas próprias necessidades". Apesar de transmitir uma mensagem clara, alertando para o dever de se planejar e executar as ações de caráter imprescindível para a sobrevivência da humanidade de forma cautelosa e tendo como norte as gerações vindouras, sua simplicidade e puerilidade acabam por minar sua legítima intenção, de certa maneira.

Isso ocorre, basicamente, porque ele parece não levar em conta o sistema produtivo que predomina e ordena as atividades humanas na atualidade, ou seja, o capitalismo. Este sistema, em sua forma vigente - o neoliberalismo -, baseia-se em relações desiguais entre uma minoria de indivíduos detentora de grandes somas de dinheiro e, por conseguinte, de poder, e uma maioria de seres humanos que não dispõem das mesmas benesses e das facilidades proporcionadas por elas ${ }^{9}$. Aliás, o número de pessoas assoladas pela miséria e pela exclusão é exorbitante, atingindo a cifra de milhões de indivíduos em todo o mundo. Dessa maneira, a preocupação com a atenção às gerações futuras, ainda que definitivamente relevante, soa um pouco inocente, já que uma parcela considerável da população mundial encontra-se, presentemente, privada de meios dignos de subsistência.

Ademais, a matriz energética utilizada nos processos produtivos e nos deslocamentos dos seres humanos é, em sua maior parte, formada por fontes não renováveis e de origem fóssil, como o petróleo, o carvão mineral e o gás ${ }^{10}$ que, além de efêmeros, são extremamente poluentes e contribuem sobremaneira com o efeito estufa e para o processo de aquecimento global

\footnotetext{
${ }^{8}$ Segundo Harari (2015, p. 341): "Essa é a pedra no sapato do capitalismo de livre mercado. Não há como garantir que os lucros sejam ganhos de forma justa, ou distribuí-los de maneira justa. Ao contrário, a ânsia por aumentar os lucros e a produção cega as pessoas para qualquer coisa que possa estar no caminho. Quando o crescimento se torna um bem supremo, irrestrito por qualquer outra consideração ética pode facilmente levar à catástrofe".

${ }^{9}$ Por exemplo, conforme Ricard (2015, p. 501): "Nos Estados Unidos, os $1 \%$ mais ricos detêm atualmente $40 \%$ da riqueza do país, ao passo que há 25 anos não possuíam mais que $13 \%$. Esse número símbolo da desigualdade foi encampado pelo movimento Occupy Wall Street e deu origem ao seu lema "somos os $99 \% "$. Ainda segundo o autor, "nos Estados Unidos, em 2011, um empresário recebia em média 253 vezes mais [dinheiro] que um simples [trabalhador] assalariado". (Id.).

${ }^{10}$ Segundo Ricard (2015, p. 577): “78\% das emissões de CO2 provêm da utilização de energias fósseis. A produção de hidrocarbonetos mais que decuplicou desde
} 1950". 
artificial. Assim, querer evocar os preceitos do desenvolvimento sustentável e não abrir mão da exploração de jazidas de petróleo, como o município de Macaé vem fazendo desde a década de 1970, soa como um paradoxo difícil de resolver e de deglutir.

E isto não é uma característica particular deste município, muito pelo contrário. É uma regra de caráter universal. O cerne da questão parece ser a importância que se dá ao aspecto econômico do desenvolvimento ${ }^{11}$, e seu constante crescimento, em detrimento das suas demais instâncias, como a ambiental, a cultural, a social e a política. Ricard (2015, pp. 592), explica que o inventor da medida de desenvolvimento econômico batizada de Produto Interno Bruto (PIB), Simon Kuznets, assinalou que ele nunca deveria ser usado para avaliar nem o bemestar, nem o progresso de uma nação. O autor também afirma que "o cálculo do PIB não faz distinção entre o aumento do volume dos bens e dos serviços, que venha acompanhado de um maior bem-estar, e o mesmo aumento, quando feito em detrimento desse bem-estar". Ele complementa sua fala ao dizer que, em alguns casos, "o PIB aumenta muito enquanto a qualidade de vida se degrada em decorrência dos danos ambientais" 12 .

Como uma alternativa de medição dos aspectos que contribuem para uma maior qualidade de vida das pessoas, Ricard (2015, p. 593) cita a criação, no Reino do Butão - pequeno país asiático situado nas cordilheiras do Himalaia - do conceito de "Felicidade Interna Bruta". Tal conceito, baseado em dados científicos, "permite mensurar diferentes aspectos da satisfação de vida e suas correlações com outros fatores extrínsecos (recursos financeiros, nível social, educação, grau de liberdade, nível de violência na sociedade, situação política) e intrínsecos (bem-estar subjetivo, otimismo ou pessimismo, egocentrismo ou altruísmo)”. Talvez este seja um método mais interessante, e inteligente, de se medir a qualidade de vida das pessoas. Além de, sem dúvida, possuir uma relação mais estreita com o conceito de desenvolvimento sustentável que se procura atingir um dia, com vistas a uma existência mais harmoniosa entre os seres humanos, em suas complexas relações, bem como entre eles e o meio ambiente no qual estão inseridos.

Assim posto, os autores deste artigo optaram por utilizar a noção de "desenvolvimento mais sustentável", relativizando o absolutismo do termo "desenvolvimento sustentável", já que compreendem que tal definição não é condizente com o modelo produtivo capitalista. Dentre as diversas atividades empreendidas pelos seres humanos, o turismo foi escolhido como objeto de análise, e pretende-se investigar a possibilidade de um desenvolvimento turístico mais sustentável, com relação às suas múltiplas esferas, em Macaé.

\section{Turismo e Desenvolvimento Sustentável}

A principal entidade de promoção e desenvolvimento internacional do turismo, a Organização Mundial do Turismo ${ }^{13}$ (OMT), com sede em Madri, e operação em caráter de fórum global para o debate de políticas turísticas, define o turismo como "as atividades das pessoas que viajam e permanecem em lugares fora de seu entorno habitual por não mais de um ano consecutivo para lazer, negócios ou outros objetivos". (Organização Mundial do Turismo, 2003b, p.18).

Tal conceituação, elementar e capaz de suscitar uma vasta gama de interpretações, parece apontar apenas para o protagonismo daqueles que viajam e das suas motivações para tal empreitada. Entretanto, esta visão simplista não abarca a totalidade do turismo enquanto fenômeno complexo, deixando de fora uma parte importante e que ora está sendo alvo de investigação, qual seja a do turismo enquanto uma atividade socioeconômica ${ }^{14}$, capaz de alterar as relações humanas nas localidades onde é implementada,

\footnotetext{
${ }^{11}$ De acordo com Ricard (2015, p. 589): "Hoje em dia, a maioria dos economistas define o crescimento em termos de aumento das riquezas - ou até de acumulação de riquezas como um objetivo em si - e de exploração dos recursos naturais".

${ }^{12}$ Com relação a isto, Ricard (2015, p. 593) cita um discurso do senador norte-americano Robert Kennedy, quando concorria à presidência dos Estados Unidos, onde o político afirmava que: "o Produto Nacional Bruto não leva em consideração a saúde de nossos filhos, a qualidade de sua educação, nem o prazer de suas brincadeiras. Não inclui a beleza de nossa poesia nem a solidez de nossos casamentos, e não inclui a beleza de nossos debates públicos nem a integridade de nossos servidores públicos. Não mede nosso humor nem nossa coragem, nossa sabedoria nem nossos conhecimentos, nossa compaixão nem nossa devoção ao país. Enfim, ele mede tudo, exceto o que dá valor à nossa vida".

${ }^{13}$ A OMT é um órgão vinculado à Organização das Nações Unidas (ONU) e tem caráter consultivo e propositivo com relação às ações e posturas que deveriam ser empregadas no desenvolvimento da atividade turística internacional e conta, atualmente, com 158 países membros, inclusive o Brasil.

${ }^{14}$ Nas palavras de Ouriques (2005, p. 27), “o turismo é uma criação e uma possibilidade do capitalismo”. Magalhães (2002, p.17) corrobora esta afirmativa quando diz que: "O surgimento do turismo, na forma como o conhecemos hoje, não foi um fato isolado. Sempre esteve ligado ao modo de produção capitalista e ao desenvolvimento tecnológico, uma vez que o primeiro determina quem viaja e o segundo como fazê-lo". Assim, apesar de os seres humanos se deslocarem pela geografia do planeta há milênios, em busca de alimentos, melhores condições de vida ou fugindo de predadores e de condições climáticas desfavoráveis, foi apenas após a revolução industrial e a consolidação do sistema capitalista de produção que os diversos componentes da atividade turística se reuniram e foram transformados em um produto para ser consumido, inicialmente, por poucos privilegiados e, posteriormente, por uma massa de trabalhadores assalariados, com direito a períodos de
} 
bem como de afetar a utilização de seus recursos naturais e promover a degradação de seu meio ambiente, caso não seja realizada de maneira consciente.

Conquanto, a OMT também cunhou uma definição para o chamado "turismo sustentável" - inspirada no conceito de "desenvolvimento sustentável" das Nações Unidas visto anteriormente - na qual afirma que ele:

Atende às necessidades dos turistas de hoje e das regiões receptoras, ao mesmo tempo em que protege e amplia as oportunidades para o futuro. É visto como um condutor ao gerenciamento de todos os recursos, de tal forma que as necessidades econômicas, sociais e estéticas possam ser satisfeitas sem desprezar a manutenção da integridade cultural, dos processos ecológicos essenciais, da diversidade biológica e dos sistemas que garantem a vida. (OMT, 2003a, p. 24).

Muito mais intrincado que o conceito de turismo elaborado pela mesma organização, ainda que tão obscuro quanto aquele, ele não cita apenas a pessoa que viaja - o turista - mas contempla as regiões receptoras, ou seja, os territórios onde se desenrolam os encontros dos visitantes com a população autóctone, que também deve ser beneficiada pela atividade. Fala, ainda, da possibilidade de proteção e ampliação de oportunidades, não esclarecendo, todavia, a que "oportunidades" alude. Além disso, faz referência à satisfação das necessidades econômicas, sociais e estéticas ${ }^{15}$, e apresenta uma preocupação com os aspectos culturais, ecológicos e biológicos de manutenção da vida. Tudo isto junto acaba produzindo uma sensação de vacuidade quanto ao que, de fato, deveria se entender como "turismo sustentável"16.

Weaver (2004, p. 580), destaca o caráter paradoxal do termo "turismo sustentável", que ele chama de "ambíguo e ilusório" e afirma que, devido à sua maleabilidade, ele pode ser apropriado "por defensores de diversas ideologias, permitindo, assim, a sua utilização para representar e defender praticamente qualquer modelo de desenvolvimento". Para o autor, "o conceito de turismo sustentável fornece um ideal e um objectivo ${ }^{17}$ para seguir em frente, e um ideal e objectivo ${ }^{18}$ largamente abraçados por princípio", ou seja, serve mais de fonte de inspiração para ações conscientes do que como uma ideia absoluta ou um fato concreto. Weaver (2004, p. 576), ao se reportar ao conceito de turismo sustentável, assevera que ele pode "significar quase tudo para todos e, no processo, torna-se essencial e efectivamente ${ }^{19}$ uma noção sem sentido e quase diabólica”.

A preocupação de Weaver com a conceituação do chamado "turismo sustentável” é mais profunda que uma mera questão semântica, pois como ele enaltece, isso pode fazer uma grande diferença em seu aspecto mais essencial, ou seja, o da criação de indicadores capazes de avaliar o grau de sustentabilidade de uma determinada ação efetiva. Para ele, a seleção, a avaliação e o monitoramento dos indicadores do turismo sustentável são entravados pela subjetividade do conceito. Além disso, ainda há o envolvimento de toda a complexidade do sistema do turismo, as singularidades de cada destino e suas realidades políticas e de orçamento. Provavelmente a mais sensata declaração com relação ao conceito seja dada por Swarbrook (2000 e, p. 121), quando diz que "talvez seja o caso de aceitarmos que o turismo totalmente sustentável seja um mito inatingível e, em vez disso, deveríamos simplesmente procurar tornar o turismo mais sustentável”20.

Independente da maneira como possa ser conceituado e interpretado o chamado “turismo sustentável”, é inegável que a atividade turística - assim como qualquer outro empreendimento humano - suscita uma série de impactos - tanto positivos, quanto negativos - no ambiente onde se desenvolve, influenciando a cultura tradicional de um local, diversificando sua economia, pressupondo ações políticas e alterando as relações sociais, não apenas daqueles que dela participam diretamente - como os turistas e os prestadores de serviços turísticos - mas de toda uma comunidade ${ }^{21}$. Para que os efeitos perversos da atividade

descanso e férias remuneradas, em busca de lugares, diferentes dos que habitualmente frequentam, para dedicarem-se ao ócio e recuperarem suas energias antes de retornar à faina diária em seus lugares de origem.

${ }^{15}$ Ainda que não explique o que deseja abranger com o termo "necessidades estéticas", criando, portanto, um hiato de compreensão neste ponto específico.

${ }^{16}$ Para Swarbrooke (2000e, p. 100), ocorre "um excesso de esperanças e talvez falte realismo e pragmatismo no debate sobre o turismo sustentável".

${ }^{17}$ Respeitando a grafia utilizada no livro, proveniente do português de Portugal, país de origem da obra em questão.

${ }^{18}$ Idem.

${ }^{19}$ Idem.

${ }^{20}$ Ainda nas palavras de Swarbrooke (2000e, p. 121): “Temos de aceitar que o turismo sustentável é uma viagem contínua para uma destinação que jamais alcançaremos, porque o turismo inteiramente sustentável é, ao que parece, inatingível, e também porque a nossa ideia do que constitui o turismo sustentável estará, sem dúvida, mudando constantemente".

${ }^{21}$ Aqui cabe a ressalva feita por Swarbrooke (2000c, pp. 62-63) de que, apesar de a ideia de "comunidade" ser confortável e aconchegante, e sugerir a noção de estabilidade e consenso, na realidade "dentro de qualquer comunidade, é provável que haja uma série de grupos com interesses muito diferentes, que terão posições diversas sobre a questão do turismo". 
turística sejam minorados e as consequências positivas sejam potencializadas, é premente a utilização de um modelo de planejamento responsável e que dê conta de tal missão 22 .

Assim, pelo até aqui exposto e para não fugir ao escopo do projeto desta edição da revista, os autores deste trabalho acreditam que os termos "turismo mais sustentável" ou “desenvolvimento turístico mais sustentável" são mais acurados para se pensar e debater as ações que visem a reduzir as sequelas nefastas da atividade turística e intensificar as benesses por ela produzidas, pois como afirma Weaver (2002, p. 574), "os exemplos de locais e destinos turísticos que satisfazem um nível demonstrável de desenvolvimento sustentável são relativamente raros e provavelmente inexistentes".

\section{Um Desenvolvimento Turístico Mais Sustentável em Macaé é Possível?}

Como visto anteriormente, a existência de uma atividade humana plenamente sustentável é utópica, ainda que possa servir de norte para a elaboração de projetos que visem implementar contínuas melhorias na qualidade de vida das pessoas, através da ampliação e da distribuição justa de renda, da conservação do meio ambiente e da cultura local e de uma melhor integração entre os cidadãos de uma determinada localidade. Com o turismo acontece exatamente o mesmo. Se bem planejado, ele pode captar recursos financeiros, ampliar a arrecadação de impostos, integrar moradores e visitantes, educar sobre a necessidade da manutenção da natureza, valorizar as manifestações populares regionais e sinalizar a importância de um trabalho contínuo de planejamento da atividade, com vistas a um benefício estendido ao maior número possível de indivíduos.

Como exemplo de desenvolvimento da atividade turística em uma localidade pode-se utilizar a cidade de Dubai, nos Emirados Árabes Unidos, que foi erigida em meio ao vazio de um deserto de areia e hoje é uma metrópole de importância global, já que funciona como o principal $h u b^{23}$ do mundo. Ela é um dos destinos turísticos mais aclamados atualmente, sobretudo pelos seus projetos inovadores e, de certa forma, megalomaníacos, além de desfrutar de uma aura de sofisticação de que foi imbuída. É interessante destacar que Dubai possui um aspecto de seu desenvolvimento econômico que a aproxima de Macaé, qual seja a dependência temporária da atividade de exploração do petróleo em determinado momento de sua história. E, justamente por esta coincidência, os autores do presente estudo decidiram traçar um breve paralelo entre ambas, guardadas as devidas proporções.

Conforme Zickwolff (2009) o petróleo foi a fonte de recursos econômicos que permitiram que Dubai se desenvolvesse de forma extremamente veloz. Com um planejamento de longo prazo, ao perceberem que as reservas daquele hidrocarboneto não eram vastas o bastante para uma produção contínua, iniciaram a diversificar seus investimentos e escolheram a atividade turística como uma das principais apostas para tal. Com isso, de uma cidade praticamente inexistente, na década de 1980, Dubai passou a figurar entre os 10 destinos mais visitados do mundo já no final da década de 2000. Apostando em projetos faraônicos, ela abriga, por exemplo, o mais alto prédio do mundo - o Burj Khalifa, com 828 metros de altura - , o maior shopping center do mundo - o Dubai Mall - e o maior conjunto de ilhas artificiais do mundo as Palms Islands, Dubai se firmou como uma metrópole dinâmica e pulsante, além de produzir riquezas e depender economicamente, cada vez menos, da atividade de exploração petrolífera.

Ao estudar o caso de Dubai, parece que a cidade atingiu um patamar inequívoco de sustentabilidade. Entretanto, o viés econômico é apenas um dos componentes do desenvolvimento de uma localidade, e o outro lado da moeda da escalada vertiginosa dubaiota não possui o mesmo brilho dourado, muito pelo contrário. Em relação ao meio ambiente, as construções das ilhas artificiais provocaram a destruição de corais, mudaram correntes marinhas e dizimaram dezenas de milhares de peixes e outros animais marinhos. Quanto à mão de obra empregada para a edificação de suas estruturas, grande parte dela vivia em regime análogo ao de escravidão, sendo proveniente, majoritariamente, da Índia e do Paquistão. A cultura tradicional local,

\footnotetext{
22 Para Hall (2002, p. 29), “embora o planejamento não seja uma panaceia para todos os males, quando totalmente voltado para processos ele pode minimizar impactos potencialmente negativos, maximizar retornos econômicos nos destinos e, dessa forma, estimular uma resposta mais positiva por parte da comunidade hospedeira em relação ao turismo no longo prazo".

${ }^{23}$ Designação em inglês para um aeroporto utilizado como centro de operações para escala de voos comerciais e organização de rotas aéreas.
} 
apesar de preservada em linhas gerais, graças ao lastro da intransigência característica do islamismo, foi permeada de influências ocidentais e muitas práticas nefastas, como o consumo de drogas e o abuso do álcool passaram a fazer parte do cotidiano da cidade.

O exemplo de Dubai serve como sinal de alerta para que se pense com cautela sobre qual a forma de desenvolvimento uma cidade pretende adotar. Macaé, outrora conhecida como "A Princesinha do Atlântico", pelo seu ar bucólico e pelas condições de balneabilidade, na primeira metade do século XX, passou a se autodenominar, em fins dos anos 1970, "A Capital Nacional do Petróleo", após a instalação da infraestrutura da então estatal Petrobrás. Esta mudança no perfil produtivo do município, outrora baseado principalmente na agricultura, na pecuária e na pesca, foi responsável pelo crescimento desordenado da cidade de Macaé, pelo inchaço de sua população, que praticamente dobrou em algumas dezenas de anos e pelo embrião de problemas sociais como a violência urbana e o tráfico de drogas (Jesus et al., 2019).

Para atender um crescente número de visitantes, atraídos pelas possibilidades de negócios, a indústria hoteleira da cidade, antes precária, passou a se desenvolver ao ponto de, hoje, ser a segunda maior do estado do Rio de Janeiro, perdendo em número de leitos apenas para a capital. Não só turistas de negócios procuravam estes empreendimentos, com o passar do tempo, diversas empresas perceberam a praticidade de hospedar seus próprios trabalhadores nos hotéis. Assim, muitos deles passaram a funcionar com uma estrutura análoga aos apart-hotéis, ou seja, oferecendo serviços específicos como lavanderia para as roupas dos hóspedes, quartos equipados com cozinhas e mobiliados conforme as necessidades dos seus habitantes, dentre outros. (Jesus et al., 2019).

Entretanto, no ano de 2014, devido a uma série de conjunturas em nível mundial (crise econômica e baixa do valor do barril do petróleo), nacional (crise da Petrobrás devido a escândalos de corrupção), estadual (desvios de quantias vultosas dos cofres públicos por uma administração corrupta) e local (esvaziamento de empresas, fechamento de lojas comerciais, alto índice de demissõe), Macaé viu os anos de bonança se esvanecerem. Todavia, após três anos à mingua, a cidade começou a apresentar melhores resultados, ainda que esteja distante de seus melhores dias. O grande problema com relação ao abalo sofrido pela confluência de reveses deveu-se, principalmente, ao fato de que Macaé não procurou diversificar de maneira mais intensa sua economia, apoiando-se fortemente sobre a exploração do petróleo. Assim, tomando como exemplo a cidade de Dubai, Macaé pode utilizar a atividade turística como uma das possíveis ferramentas de crescimento econômico. Porém, ao contrário daquela, deve prestar atenção aos aspectos sociais, ambientais e culturais do seu desenvolvimento. (Jesus et al., 2019).

Hoje, buscando a retomada do desenvolvimento econômico ${ }^{24}$, os empresários da hotelaria da cidade buscam a diversificação, atraindo um novo perfil de hóspedes, os turistas de lazer. Contando com uma boa infraestrutura e se readaptando, as unidades habitacionais passam a ser oferecias àqueles interessados em conhecer as praias da cidade e frequentar destinos do entorno, como Rio das Ostras, Cabo Frio, Búzios e Arraial do Cabo. O Polo Gastronômico Praia dos Cavaleiros, que conta com diversos estabelecimentos de alimentação, passou a organizar eventos e a oferecer novos pratos. E a Secretaria Municipal Adjunta de Turismo elaborou o Calendário de Eventos Turísticos, que conta com a realização de eventos pela iniciativa privada, mas que recebe apoio institucional de diversos órgãos da prefeitura, inclusive da Secretaria de Turismo.

Assim, ainda que a atividade petrolífera siga sendo o carro-chefe da economia local, Macaé pode se beneficiar da atividade turística e promover ações mais sustentáveis na sua execução. Todavia, como antes mencionado, mesmo que economicamente viável, a contínua exploração de petróleo não parece uma opção que possa receber um selo de "atividade sustentável”, principalmente pelos efeitos nocivos do combustível fóssil no meio ambiente, nos perigos inerentes aos vazamentos e derramamentos de óleo no oceano e pela utilização de mão de obra extremamente especializada, geralmente vinda de outras localidades e que excluem a maior parcela da população autóctone deste trabalho. Desta forma, é questionável até que ponto o esforço por uma atividade turística mais sustentável pode conviver em uma localidade que se sustenta em outra aparentemente preocupada apenas com o desenvolvimento de seu aspecto econômico.

${ }^{24}$ Sobre isto, Hall (2004, p. 31) destaca que "muitas áreas que passaram por recentes reestruturações econômicas significativas também querem agora desenvolver o turismo para atrair investimentos, promover o crescimento econômico e gerar empregos". 
A seguir, serão apresentados os cinco fatores de desenvolvimento sustentável, a saber, o ambiental, o social, o cultural, o político e o econômico, e sua relação com a atividade turística de Macaé.

\section{Turismo e sustentabilidade ambiental em Macaé}

A preocupação com a conservação do meio ambiente aparece, cada vez mais, como uma premissa para o desenvolvimento responsável de qualquer atividade. Com o turismo não é diferente. Quando se fala em "turismo sustentável", a primeira palavra que vem à mente da maioria das pessoas é "ecoturismo" 25. Entretanto, é importante compreender que eles não são sinônimos. O ecoturismo é uma segmentação que atrai pessoas dispostas a dispender seu tempo em contato com a natureza, em locais onde pode ver animais silvestres, espécimes de plantas e flores em seu ambiente natural, tomar banho de rio, explorar grutas, escalar morros e montes. Todavia, apesar desse contato direto com o meio natural, não há uma preocupação inerente com a conservação dos lugares visitados. Ou seja, uma pessoa pode muito bem ir tomar um banho de cachoeira e passear por uma trilha, mas no caminho, jogar latas de cerveja e embalagens vazias de biscoitos pelo chão, capturar animais, arrancar plantas e marcar de forma indelével rochas e pedras com pichações. Assim, acreditar que toda forma de ecoturismo é sustentável é um erro.

Com relação às empresas prestadoras de serviços turísticos, segundo Swarbrook (2000e, p. 25), "a indústria da hotelaria tem sido um dos setores que lideram o desenvolvimento de práticas mais ambientais de gerenciamento operacional". Os meios de hospedagem de Macaé que ainda não o fazem precisam, portanto, investir em práticas cada vez mais preocupadas com a conservação ambiental, como a coleta seletiva do lixo, o uso de fontes alternativas de energia - como a solar -, o aproveitamento das águas de reuso para utilização em descargas, a utilização de suprimentos reciclados de material de escritório, a instalação de dispositivos de economia de água em chuveiros e pias, dentre outros.

Macaé conta com Unidades de Conservação em seu território e que se constituem como atrativos para o ecoturismo. Algumas delas são administradas pelo Governo Federal, como o Instituto Chico Mendes de Conservação da Biodiversidade (ICMBio) e outras pelo poder público municipal, como a Área de Proteção Ambiental (APA) do Sana, o Parque Municipal Fazenda Atalaia e o Parque Natural Municipal da Restinga do Barreto. Tomando o caso específico do distrito do Sana, que é uma APA, suas características geográficas - localizado na região serrana do município de Macaé, com clima ameno, rios, cachoeiras, trilhas, morros e um ar de interior - fizeram com que pessoas dispostas a passar alguns dias distantes da vida intensa de cidades grandes a procurassem, buscando tranquilidade e contato direto com a natureza. Entretanto, com o passar do tempo, um grupo específico de pessoas inspirado pelo movimento hippie norte-americano começou a afluir para o local e introduziu o hábito do consumo de drogas, principalmente a maconha. Em pouco tempo a imagem do Sana se viu atrelada a esse costume. Hoje a localidade luta para mudar essa imagem negativa ${ }^{26}$, buscando mostrar que sua riqueza reside em seus recursos naturais e que é um local que pode receber grupos familiares e proporcionar atividades de lazer e descanso para todos.

Assim como já ocorre na Fazenda Atalaia, todas elas deveriam realizar oficinas de educação ambiental, para que os visitantes fossem informados sobre a necessidade de se conservar a natureza, as vidas animais e vegetais, a paisagem em suas nuances nativas e o equilíbrio do ecossistema. Para Western (1999, p.16), "mais visitantes estão conscientes do dano ecológico que podem provocar, do valor da vida natural e dos interesses das populações locais”. Essa consciência, aliada à educação, pode fazer grande diferença quanto a uma prática turística mais sustentável. Uma lição importante e que afeta diretamente a qualidade de um local é a que versa sobre a sua capacidade de carga.

Conforme explica Swarbrooke (2000b, p. 19), existem diversos conceitos relacionados à capacidade de carga, tais como o físico (referente ao número de turistas que um determinado local pode abrigar), o ecológico (diz respeito ao número de visitantes que podem ser alojados

\footnotetext{
${ }^{25} \mathrm{Nas}$ palavras de Swarbrooke (2000e, p.56), “o ecoturismo não tem nada de intrinsecamente sustentável”.

${ }^{26}$ Falcetta (2006, p. 32) sinaliza "a necessidade da reconstrução de uma imagem, em muitos casos bastante conhecida, para num futuro incerto reconstituir sua posição de atrativo turístico, ou seja, resgatar sua atratividade".
} 
em um lugar, antes que se produzam danos ao meio ambiente), o econômico (a quantidade máxima de viajantes que podem ser acolhidos, sem que os moradores do lugar comecem a sofrer com questões como o aumento dos preços de moradias, terrenos e de bens em geral), o social (quantidade de pessoas suportadas além do qual os danos sociais irreversíveis possam ocorrer), o cultural (número de pessoas que não deve ser ultrapassado para que não ocorram prejuízos à cultura local) e o perceptivo (máximo de pessoas que um lugar pode receber, sem que a experiência turística dos viajantes seja afetada negativamente).

Ainda sobre a ideia de capacidade de carga, também referida por Granemann (2006, pp. 124-125) como "ponto de saturação", o autor afirma que "é necessário que o fluxo de visitantes seja adequado à capacidade de recepção da região e dos equipamentos turísticos". Além disso, esclarece que "a análise da capacidade de carga turística é um instrumento que procura garantir a qualidade da oferta turística, conciliando diferentes fatores, como: satisfação dos turistas e da população residente, viabilidade econômica dos equipamentos, infraestrutura turística, qualidade do meio ambiente e tempo". Em Macaé, temos o exemplo das cachoeiras 27 do distrito do Sana, administradas desde o ano de 2017 por um empresário local. Ele implementou um modelo de capacidade de carga e constatou que o número ideal de pessoas visitando o complexo de quedas d'água seria de 100 pessoas. Além disso, passou a cobrar ingresso 28 no valor de dez reais por pessoa para ser utilizado na manutenção da sinalização das trilhas do local, compra de materiais de segurança como cordas e boias, além do pagamento de remuneração para uma equipe de monitores capacitados em educação ambiental e primeiros socorros.

Portanto, para que o turismo seja realizado de maneira mais sustentável ambientalmente em Macaé, em consonância com as demais esferas de desenvolvimento, devese, conforme afirma Swarbrooke (2000a, p. 85), "encontrar um ponto de equilíbrio entre a conservação do meio ambiente em seu estado atual e o desenvolvimento necessário para proporcionar empregos e benefícios sociais".

\section{Turismo e sustentabilidade social em Macaé}

Para que se alcancem resultados satisfatórios quanto aos aspectos sociais da atividade turística, a premissa básica é que ninguém seja impedido de participar dela, seja no papel de turista, seja no de residente local que se beneficia com os contatos com os visitantes e com os proventos trazidos por eles. Além disso, por ter uma ligação estreita com seu viés econômico, a distribuição da renda obtida com a atividade deve contribuir para que as condições de vida da população autóctone se tornem mais prósperas, fazendo do município um lugar melhor para todos, moradores e hóspedes.

Entretanto, não é incomum ocorrerem casos de exclusão ${ }^{29}$ no turismo, aliás, isto é muito comum, em vários sentidos. Em primeiro lugar, justamente quanto aos benefícios tangíveis da atividade na vida diária da população local, é possível perceber que quanto mais afastado da zona turística de uma cidade, menor a influência sentida quanto aos melhoramentos de infraestrutura urbana, serviços de esgotamento sanitário, abastecimento de água e energia elétrica, mobiliário urbano e ações de cidadania. Depois, com relação ao poder aquisitivo dos viajantes, aqueles que são identificados como de baixa renda podem sofrer com o preconceito e a inacessibilidade a determinados ambientes, como restaurantes e hotéis. Existem grupos de turistas considerados personas non gratas, alcunhados de "farofeiros", por exemplo, por viajarem levando praticamente tudo o que pretendem consumir durante sua estadia e não injetando recursos na economia local. Desse fato surge um oxímoro difícil de deslindar no conceito de sustentabilidade, ou seja, para que uma atividade seja economicamente viável ${ }^{30}$, deve atrair pessoas capazes de consumir seus serviços ou produtos, entretanto, caso elas não possuam recursos para tal, são socialmente descartadas.

Assim, surge o questionamento sobre o que é mais importante: o dinheiro que será pago para que determinada experiência aconteça a alguém; ou a experiência em si e seu benefício

\footnotetext{
${ }^{27}$ São elas, Pai, Mãe, Filho, Sete Quedas e Escorrega.

${ }^{28}$ Para Lindberg \& Huber Jr. (1999, p. 145) "a cobrança de ingressos e de outras taxas associadas ao ecoturismo pode suplementar orçamentos governamentais de conservação existentes, e fornecer incentivos para a conservação por intermédio do setor privado".

${ }^{29}$ Swarbrooke (2000d, p. 8) alerta que "devemos tomar cuidado para que a sustentabilidade e a qualidade não se tornem um pretexto para a discriminação e a segregação social". ${ }^{30}$ Para Antunes (2006, p. 210), "ao priorizar os interesses econômicos, adota-se uma postura etnocêntrica em relação aos diferentes grupos sociais
} sujeitos ao incremento turístico". 
para a pessoa, ainda que ela não possua dinheiro, mas deseje participar da atividade? Um exemplo factível pode ser visto no distrito do Sana, na região serrana de Macaé. Muitos integrantes do trade local se incomodam com a presença de visitantes que chegam naquele lugar trazendo isopores com alimentos e bebidas e procurando acessar o rio e suas cachoeiras onde não são cobradas taxas de ingresso. Essas pessoas são vistas como indesejáveis. Mas, não teriam elas o direito de desfrutar da natureza do lugar, ainda que não contribuindo financeiramente para o destino? Esse exemplo ilustra bem como o conceito de "turismo sustentável" pode ser ambíguo, baseado em conjecturas de ordem subjetiva e moral, e oco de significado.

Deve-se pensar, também, a questão da mão de obra utilizada na prestação de serviços turísticos. Segundo Magalhães,

\begin{abstract}
“é inerente à atividade turística a exploração e apropriação dos espaços físicos e sociais das comunidades, sobretudo da mão-de-obra, reconhecida como a mais mal paga do mundo, além do fato de que os cargos melhor remunerados e que exigem maior qualificação são, na maioria das vezes, preenchidos por pessoas que vêm de fora, restando aos membros da comunidade os postos menos qualificados e de baixa remuneração”. (2002, p. 19)
\end{abstract}

Já Swarbrooke (2000a, p.39) destaca que "poucos turistas poderiam estar dispostos a pagar um preço mais alto para proporcionar mais benefícios econômicos às comunidades locais". E conclui dizendo que "não parece haver evidência de exigências de turistas quanto a melhores pagamentos e condições de trabalho para empregados da indústria do turismo e da hotelaria". Assim, fica patente que o quesito da sustentabilidade social não é muito relevante para os gestores das áreas de hospitalidade em geral, sendo priorizado seu aspecto econômico e a busca por maiores lucros financeiros.

Finalmente, quando se pensa no aspecto social do desenvolvimento sustentável, não se pode deixar de fora o cuidado devido às pessoas com deficiências ${ }^{31}$, através da implementação de ações voltadas para a sua acessibilidade e a integração com o ambiente em questão e os demais indivíduos. Desta forma, o turismo precisa se tornar inclusivo, proporcionando àqueles que necessitam uma infraestrutura capaz de permitir sua circulação e o máximo de independência em relação ao auxílio de terceiros na efetiva realização de suas ações ${ }^{32}$. Henriques e Lima (2004) destacam a existência de barreiras diversificadas que atuam como entraves para o usufruto de uma experiência satisfatória pelos turistas com deficiência - tais como as barreiras instrumentais ${ }^{33}$, as arquitetônicas $^{34}$, as metodológicas 35, as programáticas ${ }^{36}$ além das humanas ${ }^{37}$ - e afirmam que apenas quando tais barreiras forem derrubadas o turismo poderá ser considerado uma atividade inclusiva.

Barros (2012) realiza um estudo abrangente e edificante com relação às adaptações necessárias aos equipamentos turísticos de alimentação e hospedagem - seja durante a realização de um projeto ou na reforma de um empreendimento já existente - e baseadas no "desenho universal" 38 que podem, e devem, se estender aos demais estabelecimentos comerciais - turísticos ou não - para a prestação de serviços com qualidade e respeito, não apenas às pessoas com deficiência ${ }^{39}$, mas também aos idosos, às gestantes, às crianças e aos indivíduos com qualquer tipo de limitação temporária. Além de indicar com precisão a maneira como devem ser realizadas as obras de confecção de calçadas, rampas, escadas, saídas de emergência, banheiros, e a disposição de sinalização pertinente nos ambientes, a autora também chama atenção para o cuidado que se deve ter ao se dirigir a essas pessoas, por exemplo, abaixando-se para falar com um cadeirante ou não elevando seu tom de voz ao se dirigir a uma pessoa surda e, principalmente, estando sempre disponível para auxiliar da

\footnotetext{
${ }^{30}$ A terminologia "pessoa portadora de deficiência" caiu em desuso, uma vez que a deficiência que uma pessoa possui não é como um objeto físico, capaz de ser abandonado em um lugar. Ela é inerente à pessoa. (Sassaki, 2003).

${ }^{31}$ Este é um aspecto muito relevante na elevação da autoestima das pessoas com deficiência.

32"São aquelas que estão instaladas nos equipamentos turísticos e não contemplam as limitações físicas e psíquicas das pessoas portadoras de deficiência proporcionando uma total dependência de outros”. Henriques e Lima (2004, p. 763).

33"As barreiras arquitetônicas em particular impedem o direito de ir e vir a qualquer local, seja um equipamento turístico ou não". Henriques e Lima (2004, p. 763-764).

34"As barreiras metodológicas são aquelas em que não é percebido o diferencial das necessidades específicas de cada pessoa, não levando em consideração suas limitações”. Henriques e Lima (2004, p. 763).

35"Se refere à legislação e sua não aplicabilidade". Henriques e Lima (2004, p. 763).

${ }^{36}$ Seriam o preconceito, a discriminação e a exclusão e contribuiriam para os problemas relacionados com a proficiência na comunicação interpessoal, o acesso à informação e questões relacionadas à autoestima. Henriques e Lima (2004, p. 763).
} 
melhor maneira qualquer um que demande algum cuidado especial. Este e outros materiais similares são de grande importância para o planejamento turístico de uma localidade preocupada com o bem estar dos seus visitantes e, por extensão, da própria população autóctone.

Assim, é imprescindível, caso Macaé deseje desenvolver uma atividade turística com vistas à sustentabilidade social, a preocupação com os aspectos da inclusão e da acessibilidade, não apenas em seus atrativos turísticos e nas empresas prestadoras de serviços relacionados à atividade, mas em toda a infraestrutura urbana, seja em praças públicas, nas calçadas, nos parques, nos estádios, nos ginásios, bem como nos terminais rodoviários e aeroviários, dentre outros.

\section{Turismo e sustentabilidade cultural em Macaé}

A preservação das identidades locais é um dos grandes desafios da atualidade, em meio a um mundo globalizado e multicultural. Para o turismo, esse tema requer atenção, visto que as características únicas de um local podem se constituir no fator motivador das viagens, ou, pelo menos, agregar valor ao produto e à experiência turística.

Em Macaé, observam-se diversos elementos culturais que permanecem preservados, enquanto outros carecem de atenção para que se tornem mais conhecidos e valorizados, tanto pelos moradores quanto pelos visitantes. Por seu crescimento populacional intenso, é grande o número de pessoas de origens variadas e nem todas conhecem a cultura macaense.

A agenda cultural do município é bastante movimentada, e existem artistas de diversos tipos atuando, como poetas, escritores, músicos, fotógrafos, entre outros. Alguns espaços destacam-se na realização de exposições, shows e peças como o Teatro Municipal.

Em termos musicais, é importante destacar aquelas instituições que estão ligadas à tradição musical de Macaé, a Sociedade Musical Nova Aurora e a Sociedade Musical Beneficente Lyra dos Conspiradores, ambas fundadas no final do século XIX, e cujas sedes são edifícios históricos. O maestro, compositor e flautista Benedito Lacerda, um dos mais ilustres músicos macaenses, parceiro de Pixinguinha em diversas gravações históricas, é uma referência no Chorinho, estilo musical que permanece exaltado em locais tradicionais da cidade.

Existem muitos edifícios históricos e espaços culturais no município, em diferentes estados de conservação, mas que têm como principal entrave à sua visitação turística os dias e horários de funcionamento - muitos são fechados nos fins de semana - além da deficiência em termos de atendimento ao turista, refletida na ausência de pessoal capacitado em recepcionar e informar aos visitantes sobre as curiosidades e estórias dos locais. Há, também, o registro de imóveis que, por falta de medidas de conservação - caso do solar apelidado de Solar dos Urubus, por sua proximidade ao antigo abatedouro municipal e consequente visita daquelas aves necrófagas - ou por simples especulação imobiliária - como ocorreu com a casa apelidada de "Bolo de Noiva", que foi demolida para dar lugar a uma agência bancária.

No que diz respeito às manifestações culturais, permanece em Macaé a farra dos Bois Pintadinhos, que completa 110 anos em 2020. A folia ocorre na época do Carnaval em diversos bairros da cidade. As lendas e histórias locais também são elementos culturais que enriquecem a experiência turística e, em Macaé, a lenda de Mota Coqueiro e a lenda de Santana são as mais conhecidas, e normalmente contadas pelos guias de turismo durante as visitas e citytours ${ }^{40}$.

O setor de gastronomia oferece ampla diversidade e qualidade de bares e restaurantes, contando inclusive com um importante polo - o Polo Gastronômico Praia dos Cavaleiros, que promove diversos eventos ligados à gastronomia ao longo do ano, o que vem contribuindo para que Macaé se consolide no setor. Apesar disso, para que a gastronomia se constitua em um elemento cultural de ainda maior relevância turística, considera-se essencial que seja elaborado um prato típico local.

\footnotetext{
${ }^{37}$ Segundo Barros (2012, p. 22), o desenho universal "significa a concepção de produtos, ambientes, programas e serviços a serem usados, até onde for possível, por todas as pessoas, sem necessidade de adaptação ou projeto específico".

${ }^{38}$ Conforme Barros (2012, p. 14), as deficiências podem ser "físicas, auditivas, visuais e intelectuais". Além disso, "as pessoas com algum tipo de deficiência somam 45 milhões no Brasil e 1 bilhão ao redor do mundo". (Barros, 2012, p. 20).

${ }^{39}$ Excursões realizadas em ônibus passando pelos principais pontos turísticos de uma cidade.
} 


\section{Turismo e sustentabilidade política em Macaé}

O aspecto político da sustentabilidade no turismo é de extrema importância para a efetivação de ações que pretendam suportar um projeto de desenvolvimento preocupado com a continuidade das ações de conservação do meio ambiente, com a melhoria da condição de vida da população local e com a ampliação e justa distribuição da receita gerada pela atividade. Segundo Silva e Shimbo (2004, p. 1), ele diz respeito à participação dos diversos "agentes sociais atuantes em seu ambiente sócio-econômico-cultural, recebendo do poder público possibilidades no controle de recursos para decisões políticas. Na escala local, o desenvolvimento encontra na forma participativa de gestão o instrumento democratizante necessário para atuação desses agentes”.

Uma das principais atribuições em âmbito legislativo por parte dos governos instituídos é a criação de leis e decretos que versem, não apenas sobre questões diretamente ligadas à atividade turística, pois como afirma Beni (2006, p. 115), "além das normas específicas sobre o turismo, as regras referentes aos temas de ordenamento, serviços, posturas, dentre outros, são essenciais para o [desenvolvimento do] turismo". O ambiente do local precisa apresentar um funcionamento coerente e coeso, para que o turismo possa se instalar e, quando isso acontecer, é necessário que a atividade turística não prejudique os demais aspectos da organização do lugar em questão.

Quanto à esfera governamental executiva, Jesus, Zickwolff, Caldas e Silva (2019, p. 288) apontam que em sua atual gestão, mesmo em meio à crise econômica que assolou a cidade recentemente, a Secretaria Municipal de Turismo "adotou estratégias de atuação baseadas na otimização de seus recursos internos ${ }^{41}$, parcerias com outras secretarias municipais e também com a iniciativa privada". Apesar do parco orçamento destinado à pasta ${ }^{42}$, o departamento conseguiu realizar ações de promoção do destino, através de mídias sociais, ${ }^{43}$ e elaborar e manter atualizado o Inventário Turístico de Macaé, documento que reúne informações sobre os atrativos, os prestadores de serviços e sobre as infraestruturas básicas e turísticas do município. Na visão de Stigliano e César (2006), tal documento é uma ferramenta de extrema relevância para o planejamento das ações diretamente relacionadas com o desenvolvimento da atividade do turismo e deve ser, por isso mesmo, constantemente checado e retificado quando necessário.

Outras atividades realizadas pela Secretaria de Turismo neste período e que foram destacadas por Jesus et al. (2019, p. 288) dizem respeito à criação e divulgação do Calendário de Eventos Turísticos de Macaé, e que é "composto por eventos realizados pela iniciativa privada e que contam com o apoio institucional ${ }^{44}$ da gestão pública", à realização de cursos de capacitação em parceria com o Centro de Educação Tecnológica e Profissional (Cetep - Macaé), e à reativação do Conselho Municipal de Turismo de Macaé, no ano de 2018, após muitos anos sem funcionamento.

A propósito, o Conselho de Turismo conta com a participação do poder público local, de diversos empreendedores da iniciativa privada e de representantes da comunidade local ${ }^{45}$, e seu resgate foi um passo importante para a democratização das tomadas de decisões concernentes às ações que poderão levar o município a desenvolver um turismo mais sustentável. Todavia, é imprescindível que este espaço de análises, debates e deliberações

\footnotetext{
40Excursões realizadas em ônibus passando pelos principais pontos turísticos de uma cidade.

${ }^{41}$ Boullón (2005, p. 23) assevera que "para que um plano de desenvolvimento tenha alguma possibilidade de aplicação, ele deve considerar a variável financeira, pois sem orçamento todos os objetivos que forem propostos, por melhores que sejam, serão irrealizáveis".

${ }^{42}$ Quanto aos baixos orçamentos dedicados à pasta de turismo nos diversos órgãos públicos, Boullón (2005, p. 25) destaca que "se a dotação de fundos que determina os orçamentos nacionais é suficiente apenas para pagar a conta de ordenados e salários, os organismos oficiais reduzem sensivelmente sua capacidade operacional e colocam em dúvida a razão de sua própria existência". Já Swarbrooke (2000c, p. 20) afirma que "muitos órgãos do setor público carecem dos recursos financeiros exigidos para cumprir uma função importante no planejamento e desenvolvimento do turismo" e acrescenta que "em geral, o setor público é apenas um ator de menor importância na indústria do turismo, com pouco controle real sobre a maior parte do produto turismo".

${ }^{43}$ Mielke $(2015$, p. 84$)$ chama atenção para o fato de que, "via de regra, as secretarias municipais de turismo (quando existem e/ou quando elas estão atreladas a outras, como por exemplo, cultura, esporte, comércio, desenvolvimento etc.) pouco ou nenhum recurso possuem para justamente promover campanhas

publicitárias para a captação de turistas", e arremata dizendo que "justamente a propaganda é uma das demandas mais solicitadas pela iniciativa privada, sobretudo os hoteleiros e os restaurantes de uma cidade".

${ }^{44}$ Além da divulgação dos eventos em meios online, há um trabalho conjunto encabeçado pela Secretaria de Turismo, mas que abrange outras secretarias, como a de mobilidade urbana, a de saúde e a de posturas, além da Guarda Municipal, responsáveis, por exemplo, pelo ordenamento do trânsito e do estacionamento durante a realização de tais eventos, pela disponibilização de banheiros químicos, pela segurança, pela montagem de palcos e pela prestação de atendimento médico.
} 
sobre a atividade turística macaense seja efetivamente utilizado para tal fim, não devendo servir a interesses particulares ou se tornando um espaço para palanque eleitoreiro. $O$ comparecimento nas reuniões, de todos os interessados em aprimorar cada vez mais o turismo em Macaé, é condição sine qua non para que novas ideias possam surgir e um trabalho sério e edificante possa tomar forma e ser colocado em prática.

Quanto às futuras ações que devem ser elaboradas pelo poder público municipal de Macaé, em suas múltiplas esferas, elas devem adotar uma visão de longo prazo para o planejamento de todas as atividades necessárias ao seu desenvolvimento mais sustentável. Sua elaboração pode ocorrer através da concepção de um Plano Municipal de Desenvolvimento Turístico ${ }^{46}$, que transcenda as questões político-partidárias e não se vincule a ideologias específicas. Seu principal objetivo é o comprometimento com a diminuição dos impactos negativos e com a multiplicação dos efeitos positivos resultantes da sua execução.

Uma dessas ações diz respeito ao diálogo com instituições que administram recursos de interesse turísticos e que, por questões burocráticas, não são transformados em atrativos turísticos passíveis de serem visitados e formalmente comercializados, sendo oferecidos como produtos em agências de viagens locais, em pacotes turísticos ou individualmente ${ }^{47}$. Como exemplos, destacam-se as ilhas do Arquipélago de Sant'Anna, sob a administração da Marinha do Brasil, com praias de águas claras e abundantes espécies da fauna marinha, convidativas para atividades de mergulho esportivo, e o Forte Marechal Hermes, gerido pelo Exército Brasileiro, e que conta com um pequeno museu de curiosidades militares, além de um hotel de trânsito e vistas panorâmicas para a cidade, o mar e para a região serrana do município.

Há também a oportunidade de se estruturar, através de cooperação mútua com o Observatório da Cidade de Macaé, um Observatório do Turismo ${ }^{48}$, preocupado especificamente com a realização de pesquisas que gerem dados capazes de balizar ações com vistas à melhoria do planejamento da atividade turística no município. A existência da Cidade Universitária de Macaé, abrigando diversos cursos de diferentes universidades públicas como a Universidade Federal Fluminense (UFF), a Universidade Federal do Rio de Janeiro (UFRJ) e a Faculdade Municipal Miguel Ângelo da Silva Santos (FeMASS), também impulsiona a possibilidade de investigar mais profundamente o turismo macaense, proporcionando espaços para debates e capacitando estudantes a atuarem como estagiários nessa empreitada.

Ainda há a expectativa da constituição de um Fundo Municipal de Turismo - cuja criação já é prevista em lei - que necessita ser efetivado a partir de uma atualização da legislação, a qual deve englobar o modelo de funcionamento e as fontes de recursos, para que se torne um instrumento efetivo a ser utilizado nas ações voltadas para o turismo em Macaé. Um modelo baseado em planejamento e gestão participativa, por meio do COMTUR (Conselho Municipal de Turismo), por exemplo, é indicado para que a aplicação de recursos desse Fundo reflita os anseios dos atores envolvidos e da sociedade macaense como um todo.

Por fim, a possibilidade de parcerias com municípios vizinhos, buscando alcançar um estágio de regionalização do turismo pode ser um grande passo. Tal iniciativa tem o potencial de estender o desenvolvimento turístico para toda a região, o que vai de encontro às políticas que vêm sendo adotadas em nível nacional desde 2004, quando Ministério do Turismo lançou o Programa de Regionalização do Turismo, além de colocar Macaé em uma posição de destino indutor de fluxos turísticos locais, beneficiando a sua imagem e a das cidades vizinhas. Além disso, a união dessas diversas administrações aumenta a força de negociação de cada uma delas frente aos órgãos estaduais e nacionais de incentivo à atividade turística, como a Secretaria de Estado de Turismo do Rio de Janeiro (SETUR) e o Ministério do Turismo (MTUR).

\footnotetext{
${ }^{45}$ Mielke (2015, p. 75) afirma que "absolutamente nenhum processo de desenvolvimento turístico responsável, no qual o objetivo seja contribuir ou proporcionar a melhora de qualidade de vida do entorno, é possível sem uma eficaz e efetiva cooperação entre os atores sociais envolvidos". Assim, "é necessário que meios de hospedagem, bares, restaurantes, guias, empresas de transporte, comércio relacionado, produção associada e poder público atuem de forma conjunta”. (id.).

${ }^{46}$ Para Vignati (2012, p. 101), “o objetivo do plano de desenvolvimento turístico é transformar recursos em produtos turísticos. Para tanto, é necessário reconhecer quais são os recursos potenciais, analisá-los e planejar uma série de ações locais”.

${ }^{47}$ Os recursos naturais e culturais são a "matéria-prima" de um atrativo turístico. Para ser considerado um atrativo, o recurso deve ser equipado com infraestrutura básica, como acesso, comunicação, proximidade com meios de hospedagem e alimentação. Por fim, ao ser somado a outros atrativos, formando um roteiro coerente, ele passa a fazer parte de um produto turístico a ser comercializado, por exemplo, na forma de um pacote turístico, juntamente com oferta de transporte, hoteleira e de restauração.

${ }^{48}$ Segundo Valls (2006, p. 159), um Observatório do Turismo é "uma ferramenta essencial para o planejamento sustentável" da atividade turística e funciona como "instrumento central de informação e análise sobre a evolução dos mercados, com característica de estabilidade e independência para a tomada de decisões do
} destino". 


\section{Turismo e sustentabilidade econômica em Macaé}

O sistema de produção capitalista, que após a queda da União das Repúblicas Socialistas Soviéticas tornou-se hegemônico e assumiu, a partir da década de 1990, sua feição neoliberal em praticamente todo o mundo, pressupõe como parte inerente de seu desenvolvimento as crises econômicas cíclicas, como aquela que afetou diretamente Macaé na década de 2010, acarretando, dentre outras consequências, a extinção de postos de trabalho, as demissões em grande escala, a estagnação financeira, o fechamento de diversos estabelecimentos comerciais, a saída de empresas estrangeiras vinculadas à exploração petrolífera e a mudança da filosofia nos empreendimentos hoteleiros da cidade, que antes atendiam prioritariamente aos trabalhadores vinculados à exploração de petróleo e passaram a diversificar seus serviços, procurando atrair turistas de lazer para suas unidades habitacionais (Silva \& Carvalho, 2019).

Chamado, durante muito tempo, de "a indústria sem chaminés", pois supostamente seria uma atividade econômica rentável e sem impactos danosos ao meio ambiente ${ }^{49}$, o turismo é, na verdade, um conjunto de prestações de serviços logicamente encadeados que ocorrem, em grande parte, de forma simultânea e que utiliza inúmeros bens de consumo para que possa se realizar. Além disso, já foi amplamente comprovado que ele degrada a natureza - assim como qualquer outra atividade humana - através da queima de combustíveis fósseis que impulsionam os meios de transportes utilizados pelos viajantes, pela poluição visual decorrente da construção de atrativos turísticos, ou pela produção de lixo e esgoto durante sua estadia em uma determinada localidade, dentre outros.

Por se tratar de uma atividade supérflua - ao menos quando se pensa nas necessidades básicas de sobrevivência de um ser humano - o turismo pode sofrer reveses e uma localidade pode passar pelo processo de esvaziamento de turistas, por exemplo, frente a uma crise econômica de grandes proporções. Além disso, muitos destinos turísticos sofrem com os efeitos da sazonalidade, ou seja, atraem um número relevante de visitantes durante determinado período do ano e, depois, passam por meses de recessão e se tornam subaproveitados. Uma das medidas viáveis para o combate desse problema, e que dever ser utilizado por Macaé, é o investimento na captação de eventos e na diversificação da segmentação, por exemplo, oferecendo serviços a nichos de mercado específicos, como os turistas de terceira idade geralmente já aposentados, com mais tempo livre e alguma reserva monetária, o que os permite viajar em qualquer época do ano.

A Cidade Universitária de Macaé pode tornar-se, caso haja interesse e ações integradas para esse fim, uma fonte de atração de eventos científicos e profissionais para o município, trazendo para Macaé um fluxo constante durante todo o ano, uma vez que um calendário desses eventos pode ser criado, evitando-se conflitos de datas entre eles. Com isso, mais uma ferramenta de combate aos efeitos perniciosos da sazonalidade passaria a beneficiar a cidade, ampliando as reservas nos hotéis e demais meios de hospedagem e incrementando o movimento de clientes em restaurantes, bares e lanchonetes, além do comércio em geral.

É muito importante que parte do montante recolhido através de impostos advindos do turismo seja investida em melhorias na infraestrutura urbana do município, o que beneficiará tanto os turistas quanto a população local, já que um dos argumentos mais exaustivamente repetidos sobre a imprescindibilidade de tais melhorias em uma localidade que se predispõe a oferecer serviços turísticos afirma que um bom lugar para se viver é, por consequência, um bom lugar para se visitar. Quanto aos lucros auferidos pela iniciativa privada, também devem ter uma parcela assegurada para o reinvestimento na atividade, evitando-se assim o sucateamento de suas instalações, bem como inovando em termos de serviços prestados, o que facilita a fidelização por parte da demanda turística, além de ampliá-la, através da publicidade espontânea gerada pelo chamado "marketing boca-a-boca" 50 .

Em sua dimensão econômica, pode-se considerar, então, que um turismo mais sustentável é aquele que transforma os investimentos - públicos e privados - feitos na

\footnotetext{
${ }^{49}$ Conforme Magalhães (2002, p. 3), para que se possa, efetivamente, realizar ações que visem a um desenvolvimento mais sustentável da atividade turística, deve-se "abandonar a crença, vigente até pouco tempo atrás, de que o turismo era uma atividade 'milagrosa' e que só trazia benefícios. Esse mito estimulou, até então, a elaboração de projetos sem a mínima preocupação com as externalidades provenientes dessa prática".

50 Que ocorre quando uma pessoa que gostou de um determinado serviço prestado, passa à frente essa informação para parentes e amigos que se tornam potenciais clientes.
} 
atividade turística em lucro para as empresas, ampliação dos negócios, arrecadação de impostos, geração de emprego e renda local e, consequentemente, na movimentação econômica em diversos setores de produtos e serviços afins. Isso acarretaria, portanto, um crescimento e uma distribuição espontânea dos ganhos monetários de maneira equilibrada ao longo do tempo e se traduziria em uma melhor qualidade de vida para todos os envolvidos.

\section{À Guisa De Conclusão}

O conceito de "desenvolvimento sustentável", como foi possível analisar ao longo deste artigo, deve ser encarado como um norte para a realização de ações factíveis e não como uma meta, pois esta seria inalcançável. A ótica da sustentabilidade oferece uma ampliação do entendimento do conceito de desenvolvimento, muitas vezes restrita ao seu aspecto econômico, que se concentra nos lucros e promove desigualdades. A partir das diretrizes da sustentabilidade, passam a ser consideradas com mais atenção as dimensões sociais, culturais, ambientais e políticas. Além disso, o viés econômico passa a se preocupar com a promoção e a disseminação de benefícios sob a forma de emprego e renda, por exemplo.

Em se tratando de Turismo Sustentável, é igualmente prudente cuidar para que a idealização não se torne um obstáculo impedindo que se realizem as ações possíveis e praticáveis. A atividade turística - assim como qualquer outra ação antrópica - gera muitos impactos - positivos e negativos - no ambiente em que se desenrola, e na comunidade que a recebe, influenciando sua cultura, sua economia e suas relações políticas. Considera-se, portanto, que somente a adoção de modelos de planejamento e gestão responsáveis em um destino turístico pode maximizar os efeitos salutares e minimizar os efeitos deletérios da atividade em um determinado destino turístico.

Nesse sentido, promover o desenvolvimento de um turismo mais sustentável em Macaé é possível e aconselhável. Não obstante, para tanto, é indispensável que o planejamento e a gestão do turismo integrem os atores do poder público municipal, da iniciativa privada e do terceiro setor em torno de um horizonte comum e de longo prazo. Portanto, o turismo como fenômeno complexo e que se conecta de forma indissociável com as demais atividades do município pode ser mais sustentável em Macaé, desde que tenha como princípios norteadores os benefícios sociais e econômicos para o maior número de pessoas, a conservação de seu patrimônio ambiental e a valorização de sua cultura, além de contar com uma estrutura política integrada e que sustente essa visão.

\section{Referências}

Altieri, M. A. (2012). Agroecologia: bases científicas para uma agricultura sustentável. (3a ed.) São Paulo, SP/ Rio de Janeiro, RJ: Expressão Popular e AS-PTA.

Antunes, R. (2006). Desenvolvimento turístico: Um olhar sobre as comunidades receptoras. In: D. RUSCHMANN, \& K. T. SOLHA (Orgs.). Planejamento turístico (pp. 201-218). Barueri, SP: Manole.

Azambuja, M. S. (Org.). O turismo e a ação das variáveis controláveis e incontroláveis (Coleção Comunicação, Vol. 37, pp. 31-47). Porto Alegre: EDIPUCRS.

Barros, C. M. (2012). Acessibilidade: Orientação para bares, restaurantes e pousadas. Rio de Janeiro: Senac Nacional.

Beni, M. C. (2006). Política e planejamento de turismo no Brasil (Série Turismo). São Paulo: Aleph.

Boullón, R. C. (2005). Os municípios turísticos (C. Valero, Trad., Coleção Turis). Bauru, SP: EDUSC.

COMISSÃO MUNDIAL SOBRE MEIO AMBIENTE E DESENVOLVIMENTO. (1991). Nosso futuro comum (2a ed.). Rio de Janeiro: Fundação Getúlio Vargas.

Falcetta, F. P. (2006). Estratégia para enfrentar crises: O grande desafio às empresas turísticas. In:

Granemann, G. L. M. (2006). Sustentabilidade turística: Avaliação multidimensional da capacidade de carga de áreas turísticas. In: D. RUSCHMANN, \& K. T. SOLHA (Orgs.). Planejamento turístico (pp. 124-153). Barueri, SP: Manole.

Hall, C. M. (2004). Planejamento turístico: Políticas, processos e relacionamentos (2a ed., Coleção Turismo Contexto, E. Sciulli, Trad.). São Paulo: Contexto. 
Harari, Y. N. (2015). Sapiens: Uma breve história da humanidade (J. Marcoantonio, Trad.). Porto Alegre: L\&PM.

Henriques, H. L., \& Lima, I. S. M. (2004). Responsabilidade social do turismo na inclusão da pessoa portadora de deficiência ou com mobilidade reduzida. In: M. BAHL (Org.). Turismo com responsabilidade social (pp. 759-768). São Paulo: Roca.

Jesus, A. C., Zickwolff, E. C. C., Caldas, G. H. S., \& Silva, L. A. (2019). A crise econômica da década de 2010 e seus efeitos sobre o turismo no município de Macaé. In: S. R. A. SILVA, \& M. R. CARVALHO (Orgs.). Macaé, do caos ao conhecimento: Olhares sobre o cenário de crise econômica (pp. 282-292). Macaé, RJ: Prefeitura Municipal de Macaé.

Lindberg, K., \& Huber Jr., R. M. (1999). Questões econômicas na gestão do ecoturismo. In: K. LINDBERG, \& D. E. HAWKINS (Ed.), Ecoturismo: Um guia para planejamento e gestão (L. C. M. Darin, Trad., pp. 143195). São Paulo: Senac São Paulo.

Magalhães, C. F. (2002). Diretrizes para o turismo sustentável em municípios. São Paulo: Roca.

Mielke, E. J. C. (2015). Comercialização em turismo: A cooperação no desenvolvimento de destinos turísticos. In: A. PANOSSO NETTO, \& M. G. R. ANSARAH (EE.). Produtos turísticos e novos segmentos de mercado: Planejamento, criação e comercialização (pp.75-90). Barueri, SP: Manole.

ORGANIZAÇÃO MUNDIAL DO TURISMO. (2003a). Guia de desenvolvimento do turismo sustentável (S. Netz, Trad.). Porto Alegre: Bookman.

ORGANIZAÇÃO MUNDIAL DO TURISMO. (2003b). Turismo internacional: Uma perspectiva global (2a ed., R. C. Costa, Trad.). Porto Alegre: Bookman.

Ouriques, H. R. (2005). A produção do turismo: Fetichismo e dependência. Campinas, SP: Alínea.

Ricard, M. (2015). A revolução do altruísmo (I. Polegato, Trad.). São Paulo: Palas Athena.

Sassaki, R. K. (2003). Terminologia sobre deficiência na era da inclusão. In: V. VIVARTA (Org.). Midia e deficiência (pp. 160-165). Brasília: Fundação Banco do Brasil.

Silva, M. R., \& Shimbo, I. (2004). A dimensão política da sustentabilidade na formulação de políticas públicas de habitação: Caso Itararé - SP e região. II Encontro da ANPPAS. Indaiatuba, SP, Brasil. 2. Recuperado de http://www.anppas.org.br/encontro_anual/encontro2/GT/GT11/michelly_ramos.pdf

Silva, S. R. A., \& Carvalho, M. R. (2019). Macaé, do caos ao conhecimento: Olhares sobre o cenário de crise econômica. Macaé, RJ: Prefeitura Municipal de Macaé.

Stigliano, B. V., \& César, P. A. B. (2006). Inventário turístico. Campinas, SP: Alínea.

Swarbrooke, J. (2000). Turismo sustentável: Conceitos e impacto ambiental. (Vol. 1, M. D. Pulido, Trad.). São Paulo: Aleph.

.J. (2000b). Turismo sustentável: Gestão e marketing. (Vol. 4, E. E. Horovitz, Trad.). São Paulo: Aleph. (2000c). Turismo sustentável: Meio ambiente e economia. (Vol. 2, E. E. Horovitz, Trad.). São Paulo: Aleph.

(2000d). Turismo sustentável: Setor público e cenários geográficos. (Vol. 3, E. E. Horovitz, Trad.). São Paulo: Aleph.

.(2000e). Turismo sustentável: Turismo cultural, ecoturismo e ética. (Vol. 5, S. Krieger, Trad.). São Paulo: Aleph.

Valls, J.-F. (2006). Gestão integral de destinos turísticos sustentáveis. (C. Vasques, \& L. Wang, Trad.). Rio de Janeiro: FGV.

Vignati, F. (2012). Gestão de destinos turísticos: Como atrair pessoas para polos, cidades e países. Rio de Janeiro: Senac Rio de Janeiro.

Weaver, D. B. (2004). O turismo e o ilusório paradigma do desenvolvimento sustentável. In: A. A. LEW, C. M. HALL, \& A. M. WILliAMS (Orgs.), Compêndio de turismo (L. C. Feio, A. André, F. Duarte, F. Oliveira, J. Pinheiro, \& J. Chaves, Trads., pp. 571-583). Lisboa: Instituto Piaget.

Western, D. (1999). Prefácio: Definindo ecoturismo. . In: K. LINDBERG, \& D. E. HAWKINS (Ed.), Ecoturismo: Um guia para planejamento e gestão (L. C. M. Darin, Trad., pp. 13-22). São Paulo: Senac São Paulo.

Zickwolff, E. C. C. (2009). A turística flor do deserto, entre o lugar e o não-lugar: Um estudo sobre a cidade de Dubai. (Monografia). Faculdade de Administração, Ciências Contábeis e Turismo, Universidade Federal Fluminense, Niterói, RJ, Brasil. 